and using systems of differing manufacture. As a first effort, such a hybrid composition would appear both desirable and necessary. When we complete the conference, however, we must ask some important questions concerning possible future activities of this sort. Should future conferences be considered? Is a more formal or specialized organizational structure needed? If additional conferences are needed, to whom should they be directed, and at what level? I do not think we should ignore these methodological questions, and I invite your suggestions.

Psychologists who use on-line computers in many ways have a special obligation to their colleagues inside and outside of psychology, which should not be ignored. While the cost of computer use has decreased in recent years, the expenditures of higher education for computing services have increased sixfold in the last 6 years (Mosmann \& Stefferud, 1971). The cost of computer use will continue to decrease. Continued reductions in the price of new systems, the increasing availability of used computer systems, the expected availability of government surplus equipment, and software advances should insure this. Current university and grant-agency economics will not, however, promote increased spending to accommodate the more widespread use of on-line computer systems. We do have an obligation to our colleagues, naive and sophisticated, to generate methods whereby efficient and appropriate applications of on-line computer systems are assured. In the past, we have been mainly dependent upon the manufacturers for applications information and advice. As many of us will testify, there is little to assure that these traditional sources need be either satisfactory or reliable. We must consider the development of methods of information exchange which are independent of the manufacturers or of chance personal acquaintances. Equally important, perhaps, is the need to develop software and hardware standards and methods tailored to on-line computer applications in psychology but independent of specific manufacturer or experimenter idiosyncrasies.

Many of the problems and obligations mentioned above suggest a need to improve communication and educational opportunities for ourselves and our colleagues. We must not forget our obligations to other members of the scholarly world. In general, administrators and undergraduates share a common problem: little direct contact with computers and computer applications (Scully, 1971). If on-line computer systems are to enjoy even wider popularity in the future, we must consider the possibility that on-line computer applications in psychology are so specialized and specialty-dependent that the appropriate education and training may not be provided by specialists from other disciplines. Just as we cannot depend upon manufacturers for information and training, we also cannot depend upon other disciplines to assume these duties.

In summary, I hope that this conference will be noted not only as a first gathering of psychologists who use on-line computers, but also as the start of an attempt to organize efforts towards improving the overall dissemination of information concerning on-line computer applications in psychology. We must consider new and better ways of assuring and expanding the appropriate use of computers in our discipline.

\section{REFERENCES}

ARMINGTON, J. C., TEPAS, D. I. KROPFL, W. J., \& HENGST, W. H. Horne and M. A. Whitcomb (Eds.), Vision research reports. Washington, D.C: National Academy of Sciences-National Research Council, 1960.

BOWDEN, L. The language of computers. American Scientist, 1970, 58, 43-53.

GREEN, B. F. Disital computers in research. New York: McGraw-Hill, 1963.

MICHAELS, P. Remote terminals replace university computer center. Electronic Systems Engineering, May/June 1970.

MOSMANN, C.. \& STEFFERUD, E. Campus computing management. Datamation, March 1971, 20-23.

SCULLY, M. G. Computers, big in research, little-used by undergraduates. The Chronicle of Higher Education, October 12, $1971,4-5$.

\title{
Various uses of minicomputers in psychology
}

\author{
JOSEPH B. SIDOWSKI \\ University of South Florida, Tampa, Florida 33620
}

I am not at all certain that the title of this presentation adequately describes what I have to say, for there are various ways to look at the "Various uses of minicomputers in psychology." A better title might have been "Who else uses these computers, so you'll know whom to contact when the lights go out" or "The various means available to psychologists for obtaining information provided by other computer users from all sorts of areas and installations to help them make the damn things work in the laboratory." Whatever, it is difficult to improve on the computer-use descriptions provided by Uttal's volume on real-time computers (1968) and those of many others who for years have attempted to educate us concerning the ways in which small computing machines might be used both on-line and in a real-time process-control sense. The forthcoming volume edited by Bernie Weiss (Digital computers in the behavioral laboratory) will update the attempt (1972). So, in the time available, I will attempt to skip through varied bits of information concerning minicomputer uses and hope, in the process, to communicate a little of something to each of you in this diversified audience.

Before going on, however, I would like to define minicomputer and will do so in spite of some disagreement within the industry concerning an exact definition. Generally, the machines are considered smaller versions of the large scale, general-purpose computers, organized in somewhat the same manner internally, allowing for similar programming techniques and for the same types of peripherals. A mini includes a central processor with general-purpose registers, core, and a set of instructions, and accepts and stores a program that the user can alter. The memory most often has a minimum of 4,096 words, with word lengths varying from 8 to 24 bits, depending on the machine and the application. The user can input commands to the system, and he receives results and instructions from it. Finally, it is small in size and costs no more than $\$ 25,000-\$ 30,000$ for the basic unit; the cost at the lower end of the scale can be less than $\$ 3,000$ (Sidowski, 1970). Beyond the above requirements, modern minis may have all sorts of features which increase capabilities and costs tremendously. For many process-control situations found in the laboratory, an off-the-shelf basic minicomputer costs little more than a specially designed logic module controller. But there is little justification for using it where a cheap hard-wired controller can do the job.

Obviously, in order to test 
SUBJECT STATION

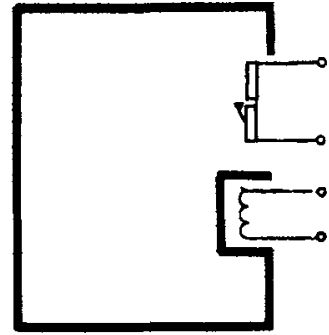

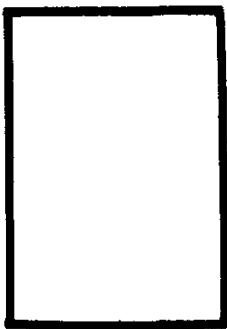

COMPUTER

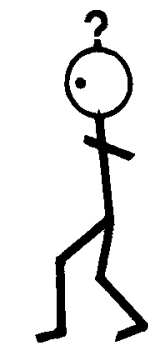

INVESTIGATOR
Fig. 1. The figure illustrates an incomplete operating system in need of a means for communication between $E$ and computer and between the computer and experimental apparatus.

experimental hypotheses in the laboratory, the $\mathrm{E}$ must have a handle on his research problem and he ordinarily would possess the necessary supportive standard equipment, such as the Skinner box, T-scope, or slide projector. For the fortunate, of course, there is a laboratory computer. Unfortunately, the fortunate are faced with two problems which require attention in order to make a research system work, namely, the programs, which act as the means of communication between the $E$ and the computer, and the interface, which is the means of connecting to and communicating between the computer and the required experimental equipment. It is hard to improve on a portrayal of the connection illustrated at the 1967 APA meetings by Louis Siegel (see Figs. 1 and 2 for a revised version).

Now that I have provided some of the definitional bounds of minicomputers, how are they used? When equipment monies were free, loose, and available, small computers were purchased by some as technically advanced laboratory decorations or, like the big pink Cadillac, as status symbols indicating the great power and strength of the researcher. Then there were those who purchased the machines in place of the less fancy desk calculators. But at the beginning of small digital computer use in psychology, and since, there have been others. In 1963, as part of the LINC Evaluation Program (and LINC, by the way, is an acronym for Laboratory Instrument Computer), several scientists, including Bernard Weiss, Don Blough, and Alan Boneau, were selected to determine whether or not psychologists and biomedical researchers could learn to use and integrate the small $2 \mathrm{~K}$ memory computer into their laboratory research endeavors. Since then, one need merely delve through the various Proceedings of the Digital Equipment Computer Users Society to note the various applications of minicomputers in psychology and the involvement of many of our colleagues in the development of its technology.

A review of the DECUS Proceedings beginning in the early 1960 s through the most recent, plus the DECUSCOPE publications and various professional journals, provide a bibliographical review which mirrors the many uses and users of minicomputers in the various areas of psychology. A complete report of this review will be concluded shortly, but I would like to convey some initial data in my talk this morning.

Looking back a mere 6 years to the Spring 1965 DECUS Conference Proceedings, I found a total of 16 reports with one article by Brazael and Booth detailing the use of a high-speed CRT display system for man-computer information processing. A second article by Savage introduced a PDP-4 monitoring system (coincidentally named the Savage system), designed and written for the Center for Cognitive Studies at Harvard with the help of Donald Norman, who modified DEC's package of two-Teletype program routines and added some useful routines for page line and spacing control. The other 14 articles had little to offer the psychologist. As an aside, it is interesting to note a few of the questions asked at that conference of only 6 years ago: "Are there going to be any more programming classes on PDP-1?" and "Can you tell me the selling price of a used PDP-1?" The answer to the latter question was that a reconditioned PDP-1 would cost in the neighborhood of $\$ 50,000-\$ 60,000$ with $4 \mathrm{~K}$ memory. Recall that in 1958 , the machine originally sold for $\$ 120,000$. Ten years after it was introduced, its more capable grandson, the PDP-8/L sold for $\$ 8,500$.

$A$ review of the Fall DECUS Proceedings of the same year (1965) resulted in three additional articles of interest: A general discussion covering the application of the LINC computer to operant conditioning research by
Boneau; a description of a message-switching system for research on human behavior in game situations by a nonpsychologist (Andreae) from the Lawrence Radiation Laboratories; and Ragsdale's description of the University of Pittsburgh's computer-assisted instructional and learning research laboratory.

Skipping ahead to the recent 1971 Spring DECUS Conference, we find ps ychologists contributing sophisticated software information. Walker and Snapper, e.g., provide a software system to control 10 different reinforcement schedules, including stimulus generation and response recording. Stout, of the Mathematical Psychology Program at the University of Michigan, describes IBIOS, which allows E-computer interaction on-line while the $S$ is being run in experiments involving learning, perception, cognition, and choice behavior. The "Son of Zoro" is listed by Lewis and Osgood as a second-generation multiprogramming system for psychological research, following up an earlier publication on Zoro. And Grabowy and Ellinwood cover an on-line system for analyzing bursts of olfactory spindle activity in EEG.

A year earlier, the 1970 Spring DECUS meetings supplied us with at least nine useful reports including several in the physiological psychology areas. One researcher (Cox), using a PDP-8/I computer with $8 \mathrm{~K}$ memory, provides a program which simulates the firing of 64 model neurons connected to form a functional nerve net with provisions for studying the possible mechanisms of learning; another describes a PDP-12 system for the on-line acquisition of heart-rate data (Kerr et al); other reports cover the study of EEG data reduction in three states bordering on light sleep (Rodgers), an application of fast Fourier transform in the automatic detection of sleep spindles (Vo-Ngoc \& Poussart), and the use of the PDP-8/I as a computer of average transients (Scott \& Dzendolet).

So, from the mid-1960s through 1971 , psychologists have reported on the use of the minicomputer in all sorts of applications. Neural, sensory, and muscle activity have been monitored, various models have been simulated, data have been analyzed, students have been instructed in a CAI (computer-aided instruction) real-time sense, and human and animal Ss have been run in studies in which the minicomputer controlled stimulus presentations, sensed and recorded responses, and, in a closed-loop manner, changed requirements for the Ss as a function of the responses being made or the criterion reached. In some 
cases, updated interval histograms have been displayed. In summary, the laboratory minicomputer can be used for data acquisition and data logging, and it can perform process monitoring and control. It can display data after acquisition, and it can store and retrieve it. Data reduction can be carried out by preprocessing and then transmitted to a larger computer for further processing, or it can be fully processed at home. And it can be used in other ways.

A number of laboratories and departments have turned to the purchase and use of time-sharing systems for the incorporation of multiple users with various experimental problems. The pros and cons of using dedicated computers vs time-sharing systems, of course, have been discussed by others and need not be drawn out here. It is important to note, however, that there are advantages and disadvantages associated with either approach. Keep in mind throughout this discussion that the more required of the computer (time shared or a dedicated stand-alone), the more expensive the system becomes because of the need for added memory, peripherals, etc.

Now there are over 100 minicomputer systems available (Sidowski, 1970). Yet an inspection of your conference program indicates that the overwhelming majority of machines listed are marketed by the Digital Equipment Corporation (DEC). For example, W. Siegel's department at Western Ontario uses a basic $4 \mathrm{~K}$ PDP-8S for operant studies; a second machine, the PDP-12 with 12K of core and peripherals, is largely devoted to perceptual experiments, although it has been used to study attitude change, personality characteristics, and human memory. Doll reports that the Department at Stony Brook (SUNY) uses a 4K PDP-8L for on-line automated verbal associate learning, recognition memory, and reaction-time studies; a second PDP-8L system with $8 \mathrm{~K}$ core has a Carousel random-access slide-projector system connected to the output lines and six response boxes inputting. Watson, at the Central Institute for the Deaf, uses the mini DEC mini, the PDP-8S, in a psychoacoustic facility to control the delivery of sounds, varying in frequency level and duration, to listeners in four booths, each containing six buffered response lines. A meter is interfaced to measure stimulus frequencies and durations, and a D/A converter is sometimes used to produce acoustic waveforms. Problems investigated include masking, pattern recognition, time intensity trading, and so on. At tonight's workshop, Wallsten will describe the

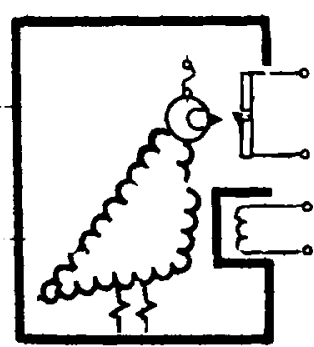

SUBJECT

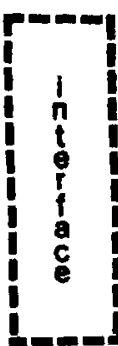

M:

COMPUTER
回皇

INVESTIGATOR

\section{OPERATING SYSTEM}

Fig. 2. A complete system with program and interface.

use of a PDP-9 in a psychometric laboratory (University of North Carolina) with the research falling into four categories: individual decision behavior, group decision behavior, problem solving, and multidimensional scaling. Aiken will discuss a $4 \mathrm{~K}$ PDP-8L with disk storage and mag tape. The latter system is located in Millward's Brown University facility and is used to study human information processing and problem solving, in particular to help investigate strategies for the solution of concept identification problems. Whitmore's PDP-12 system (University of Vermont) is used to analyze EEG data in real time from recorded data providing a graphical output and a written summary of activity and frequency changes. In G. A. Van Gelder's operation at Iowa State, a $4 \mathrm{~K}$ LINC-8 with disk and mag tape is used to analyze EEG in real time, to log data from two FI schedules simultaneously, and to log data from a Lab-K controller. J. L. Young, at Stony Brook (SUNY), employs a DEC PDP-8L computer in a system built by Infotec; this system is used also by Doll. Verbal learning experiments are run in which temporal and procedural variables are varied within the same S's trials.

Obviously, computer systems of the Digital Equipment Corporation are the most widely used in the field and are the best known. There are, however, a number of other machines installed in psychological laboratories which warrant attention also. Since several of these will be covered in talks this afternoon, and in this evening's workshop meetings, I would like to spend a few moments discussing the several minicomputers noted on your program, with the exception of the DEC and IBM machines. Specs for these systems are printed in the handouts (refer to Notes $1,2,3$, and 4).

First, note the low-cost Data General NOVA and SUPERNOVA lines, both 16-bit-word machines with easy access for interfacing. 1 The NOVA is used in a number of laboratories, and it is included in the Lehigh Valley Electronics INTERACT package. At the Memorial University in Newfoundland, for example, the Department of Psychology utilizes an $8 \mathrm{~K}$ NOVA with a number of peripherals, including a cassette tape and specially built units with 80 bits of output logic, 48 bits of input logic, and three interrupt nets. The interface is designed to produce permanent level changes and one-shot signals directly into BRS solid-state modular logic systems. This system is used primarily to run undergraduate animal and human experimental labs on-line; programming is accomplished in BASIC. At the Norwalk Hospital, Norwalk, Connecticut, two of the newer NOVA 800 CPUs are employed, each with $8 \mathrm{~K}$ core memory, a $256 \mathrm{~K}$ word disk, high-speed paper-tape reader, digital plotter, two Tektronix digital displays, a Teletype, and an IBM Selectric typewriter. One machine is being used by Nair and Fischer to automate the pulmonary function laboratory of the Department of Respiratory Technology in order to study exercise effects.

Later today, P. Van Gelder, of the Psychology Department at the University of Connecticut, will describe his application of an $8 \mathrm{~K}$ NOVA system to informationprocessing-type perceptual work with reaction time as the most useful dependent variable. In data analysis, this system has the capacity for automatically displaying the reaction-time frequency distribution.

Two SUPERNOVAs, each with 12K memory core and $256 \mathrm{~K}$ disks, are installed in the Computer Research facility of the Loma Linda Univeristy in California, along with a NOVA,800 with 8K. The latter system costs approximately $\$ 10,000$, while each of the complete SUPERNOVA systems run $\$ 30,000$ and $\$ 42,000$, 
respectively. The $\$ 42,000$ network is being used for monitoring physiological signals from human Ss. The $\$ 30,000$ SUPERNOVA system is used as a time-sharing unit, handling up to 17 simultaneous users with the BASIC language. The NOVA 800 is employed both as a laboratory and as a teaching device. Plans are to use the inexpensive 800 on a time-sharing basis and to ultimately connect it to the IBM 360 to handle the multiplexing of up to 32 graphics terminals. These terminals will be used as instructional units for students, providing both textual and pictorial representation of information. This relatively small system will have a disk and possibly $4 \mathrm{~K}$ of core added shortly.

$A$ 16K NOVA unit with a disk operating system is being used in the Dartmouth Medical School for processing EKG signals; at the Psychiatric Clinic of BEL-AIR in Switzerland, a 4K NOVA system and seven-track analog tape recorder are utilized to diagnose and analyze sleep patterns. Computer analyses are carried out on data from eye movements, heart rate, and respiration. In the Department of Biochemistry and Biophysics at Texas A \& M, Professor Meyer is using a NOVA to drive a display system that could be described as three-dimensional.

At the University of Notre Dame, H. Esch, of the Biology Department, is employing the newer NOVA 1200 (priced with 4K 16-bit words and 1,200-nsec memory cycle time at $\$ 5,450$ ) with $8 \mathrm{~K}$ memory in an on-line analysis of electrophysiological data (control of insect flight). A second researcher uses the system off-line to evaluate and plot the daily activity of mosquitoes from data stored on paper tape.

A little-known machine in the behavioral sciences is the IMLAC PDS-1, a stand-alone, programmable, display computer system. ${ }^{2}$ The PDS-1 comprises a 14-in. CRT display screen, a processor, and a solid-state keyboard with software-programmed functions. The CRT is refreshed from local memory at 40 frames/sec normally and can display about 1,200 characters or 500/800 in. of graphics, or combinations of characters and graphics, depending on the efficienry of the character and graphics definitions in the display list. The operator is able to make any number of deletions, insertions, or changes of characters or graphics. The graphics capability includes the generation of eight 1/8-in.-long directional vectors in keyboard graphics mode. It is possible also to generate large eight-character-length vectors along four major axes. These vectors, and smaller ones used to draw smooth curves, can be transmitted in eight-level code. The two-processor system has a central processor for developing display lists which guide the CRT display processor. The memory (4K expandable to $32 \mathrm{~K}$ 16-bit words) can be accessed by both processors.

At the University of Washington, Seattle, Drs. Nancy Frost and E. Hunt use an IMLAC PDS-1 for measuring stimulus-reaction times and for studying verbal memory abilities, digit span, and two-choice reaction-time performance, all using text displays. The minicomputer system has also been programmed to run visual tracking types of decision-making experiments with pictorial displays.

Turning to the Hewlett-Packard minicomputer line, ${ }^{3}$ we find that most have been applied in the biomedical areas. There are, however, a number in psychology departments, with one of the exceptionally large systems being at UCLA. A departmental time-shared system, the HP-2116 computer utilizes $32 \mathrm{~K}$ 16-bit words of memory and includes teleprinters, paper-tape punches, card reader, and magnetic-tape unit, along with other peripherals. The entire system is under the control of a Hewlett-Packard real-time executive software operating system which allows members of the Psychology Department to conduct experiments in a real-time priority-oriented multiprogramming environment. At the same time, the system allows low-priority activities such as programming, compilation, debugging, data conversion to magnetic tape, card reading, and other activities to take place. On-line labs connected to the computer are equipped with 12-character keyboards to provide communication with the machine; up to 12 stepping motors, 1 in each lab if necessary, can be operated simultaneously. A random-access slide projector can be programmed to display any one of 80 slides upon request, and the user can program display orders and directions dependent upon the S's response. The system card reader, of course, can be used for grading exams and for cecording and analyzing the results of questionnaires or tests. The UCLA HP-2116 system can process simple geometric pictures for visual display either on an oscilloscope or an $x-y$ plotter, and the computer provides for control of certain waveforms and pitch scales in audition, as well as for various parameters in vision experiments.

In addition, at the UCLA Perceptual Systems Laboratory, Dr. Carterette and his colleagues have a dedicated HP-2116B, with $16 \mathrm{~K}$ of memory, tied to a moving-head disk drive. This particular Hewlett-Packard package will not be discussed further because the various uses of the system in the study of psychological and physiological acoustic experiments, as well as some visual studies, will be detailed in the workshop tonight. For interested researchers, the $\mathrm{HP}-2116 \mathrm{~B}$ is described in the handout, along with its successors, the more inexpensive HP-2116C and 2100A. ${ }^{3}$ (The GA 18/30 system, the application of which will be discussed later today, is described also. ${ }^{4}$ )

Note that the above systems with peripherals are very expensive and, as with some of the DEC and NOVA systems noted, exceed the $\$ 25,000-\$ 30,000$ limit placed on the minicomputer definition. The original minimal basic package for the HP-2116B, however, was priced at $\$ 24,000$; for the $2116 \mathrm{C}$ with $8 \mathrm{~K}$, it is $\$ 14,000$. So we are still in the ballpark. 3

To overcome the financial cost problem, some researchers have turned to government surplus equipment. Several years ago, Dr. Beck, an engineer at Tulane University, proposed that obsolete Minuteman I general-purpose airborne computers, costing \$234,000 each with related test equipment, be put to work for research and education in the United States. Today more than a hundred labs, universities, and industries have the machines. Rather than scrapping the obsolete D17B guidance computer, the government has virtually given the systems to any institution working under a federal contract or grant. It is interesting to note that approximately 800 Minuteman D17B computers will be declared excess by the USAF through 1974.

Of course, the required interfacing of these systems is a problem. Beck reports an implementation of the system for $\$ 525$, including the price of a Flexowriter. The reports of other users indicate the hookup price to be low also. But technical help must be available to do the job. So, before rushing off for a $D 17 B$, be sure that someone in the laboratory is well trained in the fundamentals of electronics and is willing to do the necessary work.

Note the description of the computer in your handout and the mailing address for acquisition information. ${ }^{5}$ The D17B has a 2,700-word 24-bit/word disk memory and a word time of 78 microsec-not exactly the speediest in the business. The delay-type memory is a ferrous-oxide-coated magnetic disk which rotates at $6,000 \mathrm{rpm}$. Each memory channel contains 128 of the 24-bit words. Program and data characters can be read into the 
machine at 800 5-bit char/sec or taken from a keyboard entry. Forty-three discrete input lines are under program control. Program-controlled outputs include a 4-bit character out, with parity, a 5-bit register controlling 28 discrete output lines, 12 analog voltage outputs, and pulse-type output lines. Execution time for basic instructions is one word time for either 11-bit single-precision or 24-bit double-precision data. Parallel processing (execution of two identical single-precision add, subtract, shift, or multiple instructions) is possible, and hardware divide is available. There are eight rapid-access memory loops. Instruction repertoire contains 39 separate codes. And discrete output lines can be used to sequence experiments involving very accurate timing.

In response to the interfacing problem, the Autonetics Division of North American recently announced the marketing of a D17B input/output device in two configurations: 5 an interface device including an ASR-33 Teletype for $\$ 5,200$, and the same package without the ASR-33 for $\$ 3,500$. Computer mode control switches are installed on the dial panel of the Teletype. The system adds multiplexed ADC capability to the computer and provides capability for bulk data storage expansion with an optional mega-bit tape cassette. A suggested layout, with the computer, power supply, and venting system located under a desk-type enclosure, is shown in Fig. 3. Of course, the cost of such a commercial interface device removes the $D 17 \mathrm{~B}$ from the inexpensive surplus equipment money market. It adds a cost that might better be applied to the purchase price of one of the many inexpensive minicomputers listed elsewhere (Sidowski, 1970).

A list of Minuteman computer owners of interest to psychologists is included in your handout. ${ }^{6}$ The users' group totals over 100, and it is very active in providing the necessary know-how for setting up the D17B, operating it, and servicing. The group shares programming and spare parts at little or no cost.

L. Happel, Department of Neurology at the Louisiana State University Medical Center in New Orleans, is working with two D17Bs in biomedical research. Total cost for the development of the two machines has been between $\$ 800$ and $\$ 1,000$. The computers are interfaced to a typewriter and also to a small Fabritek computer of average transients; the total system appears to be very effective. In another installation, at the Center for Computer Assisted Instruction, Florida State University,

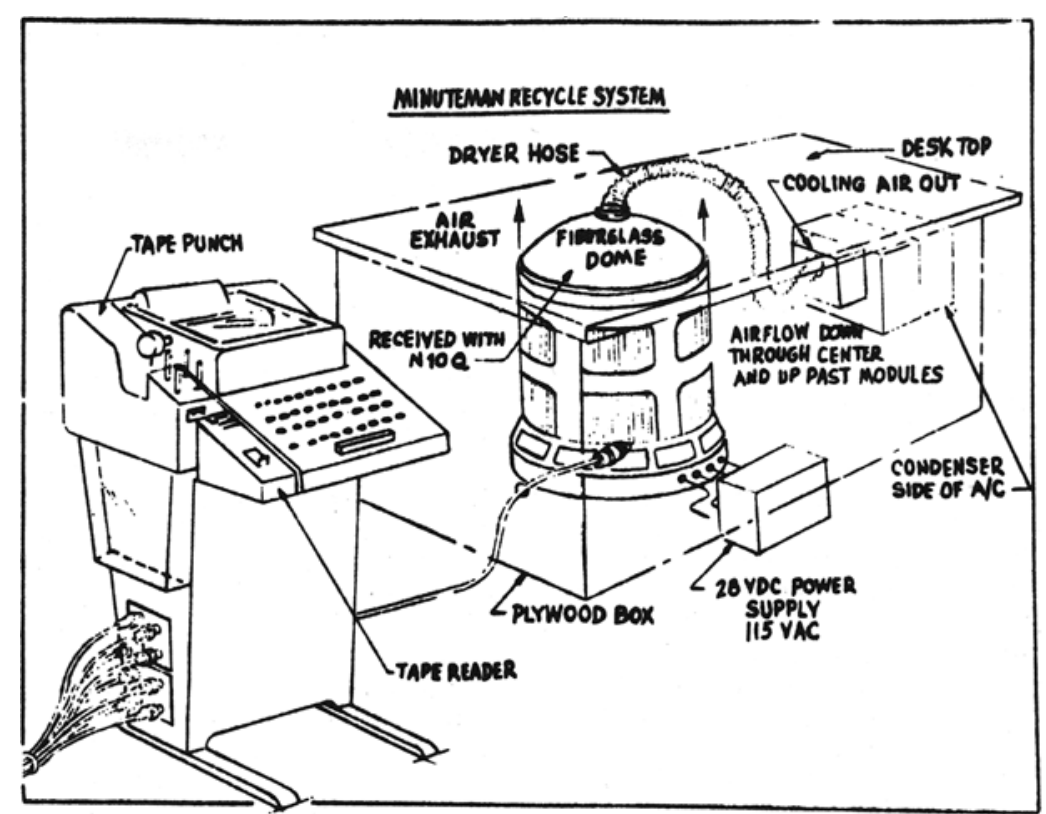

Fig. 3. Minuteman D17B computer (cylindrical with fiberglass dome) stored under a desk-top-type encasement, along with power supply and cooling system.

the design of a cooling system, manual control panel, and Flexowriter interface have been completed, and it appears that the conversion will be accomplished for less than $\$ 500$. The unit will be used for training and psychological testing. The Psychology Department Computer Lab at the University of Colorado, together with the Department of Electrical Engineering, is developing a graphics program around two D17B computers which will be used to drive interactive terminals with video man-machine interfaces. On the other hand, because of the technical requirements necessary for making modifications, the machine in the Psychology Department at Bowling Green University is as yet unused.

If we direct our attention to more all-inclusive "turnkey" packages, two software/interface computer systems are offered by psychological equipment firms. These are the Lehigh Valley Electronics (LVE) INTERACT and the Grason-Stadler SCAT systems. The INTERACT system has been installed or contracted for by six universities. These include the systems of J. R. Millenson, University of Oxford, who designed and uses the ACT language with his own hardware and computer, and Harry Coppock at the University of Wisconsin-Kenosha, who purchased an eight-station INTERACT with a PDP-8L 8K CPU and a special audio package to be shared with the Physics Department. Keith Rodewald at Central Michigan University has a four-station INTERACT system using a PDP-8/I $8 \mathrm{~K}$ unit for running pigeons in student lab-type boxes. Alan Kamil's INTERACT system at the University of Massachusetts is used to run rats in avoidance programs; the system is shared with others. The most recent INTERACT systems have been purchased by Northern Michigan University and the University of Winnipeg. The former installation is a four-station system with a $4 \mathrm{~K}$ NOVA computer unit for running animals on complex avoidance schedules. The Winnipeg installation is an eight-station system with a $16 \mathrm{~K}$ NOVA. It will serve as a multiuser system for several investigators requiring complex matching programs and a great deal of output data.

The Grason-Stadler SCAT package is in six permanent installations. A seventh SCAT software/interface segment was used temporarily by Bemie Weiss (University of Rochester, Department of Radiation Biology and Biophysics) on a loan basis for purposes of system evaluation.

The SCAT system at the University of Wisconsin Regional Primate Research Center will be discussed at this meeting by John Davenport, so nothing further will be said concerning its function. An additional unit is installed in Professor Amsel's laboratory at the University of Texas, Austin. The PDP-8/I system is used in the study of performance in the runway maze and the activity wheel, with provisions provided for typical parameters such as shock and reinforcement. A SCAT installation at the Aberdeen Proving Grounds has a $16 \mathrm{~K}$ DEC computer, and it is used to 
study the short-term memory of human Ss. At the University of Texas Medical School in Galveston (REACT Center), $R$. Benton is using SCAT in $h$ is work on the vocational rehabilitation of the hard-core unemployed. Basically, the machine is used as a data logger, while providing some experimental control with feedback. A work table is provided on which Ss are required to dismantle vacuum cleaners, auto carburators, and other devices and to carry out typical stockroom logging work. The SCAT system is used for timing, sequencing, and for providing knowledge of results. The Department of Psychology at Florida State University (J. Gilbert) has a $12 \mathrm{~K}$ core SCAT system and time shares 24 h a day. The system services a number of people in several areas in the department. Generally, compiling is done off-line on a PDP-8 or PDP-12. Finally, a five-station $8 \mathrm{~K}$ system is used to monitor animal activity in 10 cages at the Rudolph Magnus Institute, University of Utrecht, The Netherlands.

Now, if the DEC computers are the most widely used minimachines in the world, the Digital Equipment Computer Users Society (DECUS) is its most valuable adjunct. Because of the Society's orientation toward software and hardware information exchange and because of its program library, DECUS often serves as a highly valuable and respected "security blanket" which helps draw new computer purchasers to DEC products. In 1961, DECUS had six members. In 1964 the membership grew to 109 , followed by 850 in 1966 , 2,008 in 1967 , and 9,110 in 1970 . Indeed, during the past year, the membership grew by $50 \%$. The most recent figures show the DEC User's Society membership exceeding 10,000. DECUS meetings are held in the spring and fall of each year, and paper presentations covering various aspects of computer use and technology are published in the Proceedings; annual Proceedings report the European and Canadian conferences, respectively. Program Library Catalogs are available to users, as is DECUSCOPE, a publication originally released as a newsletter, but which over time has published an increasing number of technical articles covering useful bits of information on DEC software and hardware. Now a technical journal is planned which will publish submitted articles covering DEC products.

Even JUG (the Joint Users Group) and LUGS (local Users Groups) have been organized. JUG plans to publish a combined Program Library Directory, the first issue of which will contain 1,000 programs.
Turning to other companies, the Data General Corporation Computer Users Group (NOVA and SUPERNOVA), although relatively new, is growing rapidly, with over 2,000 machines installed. Users report general satisfaction with company support and are pleased with the computer products and prices. But many voice concern over the present level of software support and user information exchange, as might be expected of a relatively new company (the first NOVA computer was exhibited publicly in 1968). Of course, the group's program library is expanding and users' meetings are scheduled regularly for purposes of information exchange.

The Varian Data Machines Users Group lists over 300 members in various disciplines and industries. Most systems of interest to psychologists are in the physiological areas. The recent announcement of several new medical and physiological system packages will probably increase the number of users in these categories. (The MR-20 medical research system, for example, includes a $12 \mathrm{~K} 620 / \mathrm{L}$ 16-bit word computer, a $61 \mathrm{~K}$ fixed-head disk, a teleprinter, an analog input/output subsystem, computer option package, all necessary cabling and cabinetry, standard Varian software package, and Extended Basic for $\$ 27,740$. )

Information covering a sampling of users groups may be obtained from the addresses listed in your handout. $9,10,11,12$

If we shift our attention away from examining computer uses through machine-type or user-group information exchanges, it is interesting to note the citations of minicomputers in professional psychological journals. I have reviewed some of the 1971 issues of various journals and found the following: In four issues of the Journal of Verbal Learning and Verbal Behavior, containing a total of 63 articles, no on-line computer was cited, although a few authors noted the use of random stimulus lists generated by large machines. Three issues of the Journal of the Experimental Analysis of Behavior showed 52 articles with two citing minicomputers-in one case, a PDP-8 was used in a monkey study of generalization gradients of response latency, and in the second report, a PDP-8/I with $4 \mathrm{~K}$ was used to program all parameters, delay times, etc., in a multiple-choice test of monkey short-term spatial memory. Four issues of Psychophysiology showed five citations in 50 articles, with the LINC being used to compute average evoked responses and to generate and control stimuli in two studies, and the same basic type of computer employed to read intervals between successive $R$-waves in an investigation of heart rate during infancy. Reviewing five issues of the Journal of Experimental Psychology resulted in a total of 141 publications with only five or six referencing minicomputer use. One study dealt with verbal memory and reaction time and another, with the effect of masking tone on auditory images. In a short-term memory experiment, a minicomputer was used to generate and display stimuli on a CRT and to monitor Ss' responses and perform initial data tabulations. Hill interfaced a LINC-8 to an array of 24 airjet tactual stimulators, or to a visual display box with a 24-lamp array, to investigate the processing of tactual and visual point stimuli sequentially presented at high rates. Three randomly selected 1971 issues of the Journal of Comparative and Physiological Psychology showed two citations; five copies of Perception and Psychophysics indicated that 9 of the 57 articles cited the employment of on-line minimachines, with the old standbys, Uttal, Pollack, and Mayzner, contributing to the group. I say old standbys because in my recent review with Ken Carter of a number of psychological journals covering the years $1965-1970,11$ authors provided $52 \%$ of the minicomputer citations. Among these were Blough, Pribram, Bliss, Mayzner, Uttal, Weiss, and Pollack. The same survey indicated that $77 \%$ of the on-line computers used in the research were DEC machines, with the PDP-8 and LINC citations dominating. In classifying usage, $43 \%$ of the minicomputers were employed to control stimulus presentations and reinforcements, to collect data, and to display information in a real-time experimental control sense; $29 \%$ of the machines were used strictly for data handling and reduction. The remainder of the applications included simulations, dedicated stimulus control, etc.

As promised, this has been a skip-through of the uses of minicomputers. More detailed coverages will be presented by others. Before signing off, however, I would like to leave you with one detailed example from the laboratories of J. R. Millenson of Oxford, England.

Millenson and Jacobs are currently using the ACT (Automatic Contingency Translator) language to a tomate a series of visual psychophysical experiments with doves. The birds are trained to discriminate visual flashes, their numerosity, hue, angular separation, or form. The dove's performance is used to measure visual fields, acuity, interocular relationships, and 
monocular bias. Visual stimuli are presented by a slide projector located above the plane of the apparatus, the beam of which passes through a splitting system. The split beam then passes via two electromechanical shutters onto tilting mirrors. When these individual shutters open, images projected from the slide are reflected down into the animal $S$ apparatus, where they are focused onto two tangential vertical screens and act as discriminative stimuli. The dove stands in the center of this array in a confining transparent box, which allows the bird access to a food hopper and three vertically arrayed keys. A trial starts with the lighting of an observing keylight. When the key is pecked, a shutter opens for a short time and exposes one of two stimuli projected from the slide. Concurrently, the two response keys are illuminated and the dove is required to respond to one of the two. If the response is correct, the bird is allowed 3 sec of access to grain on a proportion of trials. Incorrect responses, on the other hand, result in time-out in darkness with the same probability. After the trial, events are recorded by counters or by the program, the next stimulus slide is selected, and another trial begins.

The houselights, three keylights, food magazine, counters, shutters, projector slide-tray, and optical wedge motor are all controlled by the computerized system. However, the number of controlled devices exceeds the maximum of 11 stimulus bits available, so 5 bits of the stimulus bank have been gated via conventional transistor logic; any combination of these specifies a unique output line. Thus, 38 possible stimulus lines are available, 6 independent and $2^{5}$ gated.

Millenson is using the same PDP-8/S in ACT mode in a series of studies of conditioned emotional-response effects on a variety of behavioral baselines. In collaboration with DeVilliers, one experiment involves a two-lever concurrent variable milk reinforcement schedule, with the two levers associated with different reinforcement durations. A "danger" stimulus is presented at variable time intervals. When present, brief grid shocks occur randomly.

The computer/ACT system controls reinforcement contingencies and adjusts reinforcement durations, change-over delays, and shock properties as a function of the rat's responses. The program is responsible also for controlling ink recorders and for printing out comparative response data in safe and "danger" periods. This study, and the psychophysical dove research, are managed jointly. More details of the methodology may be found in Millenson's chapter in the forthcoming book Digital computers in the behavioral laboratory (1972).

Refer to Alleman and Platt (1972) for an interesting application of the PDP-8/I to the study of differential reinforcement of interresponse times, with controlled probability of reinforcement per response of pigeons.

Now, if only the doves, rats, and pigeons could be taught to appreciate and understand the English language. Then, as some human Ss are, they could be ushered into the experimental chamber and shaped to start the study by striking a key, following which the machine would take over and say "Hello: I am a minicomputer, and I am working as a properly programmed psychologist." And it would automatically go on from there.

\section{REFERENCES}

ALleman, H. D., \& PLATT, J. R. Differential reinforcement of interresponse times with controlled probability of reinforcement per response. Learning \& Motivation, 1972 , in press.

ANDREAE, S. Message switching system using the PDP-5. In: DECUS Proceedings, Fall 1965. Maynard, Mass: Digital Equipment Computer Users Society, 1966. Pp. 55-64.

BONEAU, C. A. Application of the LINC computer to operant conditioning. In: DECUS Proceedings, Fall 1965. Maynard, Mass: Digital Equipment Computer Users Society, 1966. Pp. 41-44.

BRAZEAL, E. H., JR., \& BOOTH, T. L. A high-speed man-computer communcation system. In: DECUS Proceedings, Spring 1965. Maynard, Mass: Digital Equipment Computer Users Society, 1965. Pp. 33-46.

CoX, B. Simulation of neural nets. In: DECUS Proceedings, Spring 1970. Maynard, Mass: Digital Equipment Computer Users Society, 1970. Pp. 203-207.

GRABOWY, R. S., \& ELLINWOOD, E. H, JR. On-line detection of EEG spindle activity. In: DECUS Proceedings, Spring 1971. Maynard, Mass: Digital Equipment Computer Users Society, 1971 . Pp. 85-87.

KER R, J ., WILLIAMS, T. A., KHACHATURIAN, J.S., MILKMAN, N., \& TOBIN, M. A PDP-12 system for on-line acquisition of heart rate data. In: DECUS Proceedings, Spring 1970. Maynard, Mass: Digital Equipment Computer Users Society, 1970. Pp. 273-275. LEWIS, J. L., \& OSGOOD, G. W. Son of ZOR O: A second generation multiprogramming system for psychological research. In: DECUS Proceedings, Spring 1971. Maynard, Mass: Digital Equipment Computer Users Society, 1971. Pp. 73-74.

MILLENSON, J. R. On-line sequential control of experiments by an automated contingency translator. In B. Weiss (Ed.), Digital computers in the behavioral laboratory. New York: Appleton-Century-Crofts, 1972 , in press. RAGSDALE, R. G. The learning research and development center's computer assisted laboratory. In: DECUS Proceedings, Fall 1965. Maynard, Mass: Digital Equipment Computer Users Society, 1966. Pp. 65-68.

RODGERS, G. F. A study in EEG data reduction. In: DECUS Proceedings, Spring 1970. Maynard, Mass: Digital Equipment Computer Users Society, 1970. Pp. 291-296.

SAVAGE, B. I. A monitor system. In:
DECUS Proceedings, Spring 1965. Maynard, Mass: Digital Equipment Computer Users Society, 1965. Pp. 93-127.

SCOTT, D. E., \& DZENDOLET, E. The PDP-8/I as a CAT. In: DECUS Proceedings, Spring 1970. Maynard, Mass: Digital Equipment Computer Users Society, 1970. Pp. 301-303.

SIDOWSKI, J. B. Minicomputers. Behavior Research Methods \& Instrumentation, 1970, 2, 267-288.

STOUT, $R$. L. IBIOS-an interactive buffered input-output system for the LINC-8. In: DECUS Proceedings, Spring 1971. May nard, Mass: Digital Equipment Computer Users Society, 1971 . Pp. 39-42.

UTTAL, W. R. Real time computers: Technique and applications in the psychological sciences. New Y ork: Harper \& Row, 1968.

VO-NGOC, B., \& POUSSART, D. An application of the FFT in automatic detection of sleep spindles. In: DECUS Proceedings, Spring 1970. Maynard, Mass: Digital Equipment Computer U sers Society, 1970. PD. 297-300.

WALKER, A., \& SNAPPER, A. G. Improvements to the SKED processor control software system. In: DECUS Proceedings, Spring 1971. Maynard, Mass: Digital Equipment Computer Users Society, 1971. Pp. 7-12.

WEISS, B. (Ed.) Digital computers in the behavioral laboratory. New York: Appleton-Century-Crofts, 1972 , in press.

\section{NOTES}

\section{Data General Corporation}

Route 9

Southboro, Mass. 01772

\section{NOVA}

The original NOVA is a 16-bit machine with four accumulators, two of which may be used as index registers. It offers a choice of core or read-only memory of $1 \mathrm{~K}, 2 \mathrm{~K}, 4 \mathrm{~K}$, $8 \mathrm{~K}$, and up to $32 \mathrm{~K}$ (using an optional expansion chassis) 16-bit words. Direct addressing is required for the balance of memory. Number of instructions: 200 . Total memory cycle time depends on the type of module accessed; 2.6 microsec is required for a $4 \mathrm{~K}$ module, 3.9 microsec for a $2 \mathrm{~K}$ core, $6.5 \mathrm{microsec}$ for a $1 \mathrm{~K}$ core, and 2.4 microsec for a $1 \mathrm{~K}$ read-only module. With a $4 \mathrm{~K}$ core module, typical add instruction time is less than 5.9 microsec. $\mathrm{Up}$ to 62 devices may be connected to the I/ 0 bus and may be individually selected by the central processor.

NOVA comes in desk-top console or in a 51/-in.-tall standard rack-mount package. Both basic versions can hold up to $20 \mathrm{~K}$ 16-bit words of memory or interfaces without expansion chassis. The standard $4 \mathrm{~K}$ configuration with Teletype interface was priced at $\$ 7,950$.

\section{SUPERNOVA}

SUPERNOVA has the same basic configuration as the NOVA: 16-bit word. four accumulators, interchangeable core and read-only memory, and the same packaging design. This computer, however, is considerably faster than the NOVA. A full memory cycle using core takes 800 nsec for the SUPERNOVA $(2.6 \mathrm{microsec}$ for the NOVA). Using read-only memory, cycle time is 300 nsec for SUPERNOVA and 2.4 microsec for the NOVA. SUPERNOVA overlaps the fetch and execute portions of arithmetic and logical instructions from read-only memory, so two numbers can be added in one 300 -nsec memory cycle. The machine operates in fully parallel fashion on its 16-bit words-all 16 bits at once in a single 300-nsec machine cycle. With the NOVA, the word is divided into four 4-bit nibbles that require four 400-nsec cycles to process. 
With 4K of core memory, Teletype interface, and automatic program load, SUPERNOVA had been priced at $\$ 11,700$. As of August 1, 1970, a new price of $\$ 9,600$ was announced for the same configuration. The SUPERNOVA central processor has been reduced from $\$ 6,850$ to $\$ 5,600$, and 4K 16-bit memory subsystems have been reduced from $\$ 4,500$ to $\$ 3,650$. The ASR-33 is priced at about $\$ 1,400$. Multiply-divide and memory protection are options.

NOVA was announce 1 in 1968 and first shipped about 2 years ago. The SUPERNOVA was introduced in 1969, and the first machines were delivered in 1970 . Both models sold exceptionally well.

The above machines have been succeeded by three new computers: NOVA $1200(\$ 5,450)$, NOVA 800 $(\$ 6,950)$, and SUPERNOVA SC $(\$ 11,900)$. NOVA 1200 is a 16-bit multi-accumulator machine with 1,200-nsec memory cycle time. NOVA 800 has a basic memory cycle time of 800 nsec. SUPERNOVA SC has a monolithic memory which, with overlapping instruction retrieval and execution, give it the ability to execute arithmetic and logical instructions in a single 300 -nsec memory cycle.

\section{IMLAC Corporation \\ 296 Newton Street}

Waltham, Mass. 02154

PDS-1

The PDS-1 is a programmable stand-alone display computer system which has been priced at about $\$ 10,000$ for the basic unit. The system comprises a CRT display screen, a central processor, and a solid-state keyboard with software-programmed tunctions. The CRT screen is capable of displaying about 1,200 flicker-free characters, and it may be oriented horizontally or vertically. The 14-in. CRT is refreshed from local memory at, normally, 40 frames/second. CPU word size is 16 bits, and memory size is $4 \mathrm{~K}$ words, expandable to 32K. Cycle time is 2 microsec; direct addressing. $2 \mathrm{~K}$ words, with indirect addressing at $32 \mathrm{~K}$ single level. The CPU has 16 index registers (auto). I/O maximum word rate is $500 \mathrm{kHz}$.

As a standard package, the IMLAC PDS-1 comes with a text and graphics-editing program. A proprietary interactive graphics pattern permits line-drawing graphics editing from the keyboard, as well as limited text.

\section{Hewlett-Packard}

Cupertino Division

11000 Wolf, Road

Cupertino, Calif. 95014

HP-2116B

The HP-2116B has an 8K memory, expandable to $32 \mathrm{~K}$, with 16-bit word lensth. Memory cycle time is 1.6 microsec, add time is 3.2 microsec, and multiply is 19.2 microsec. The computer has 16 priority interrupts in the standard package, expandable to 48 . Maximum $1 / 0$ is $600 \mathrm{kbytes} / \mathrm{second}$. The machine has 72 baric instructions and seven hardware redsters. Software includes FORTRAN IV. ALGOL, Basic, and real-time executive. Original price of the basic pactsage was about $\$ 24,000$. An additional $8 K$ memory was $\$ 10,000$.

HP-2116C

The newer HP-2116C basic package also includes an 8K memory (16-bit processor). self-contained power supplies, and 16 input/output channels. Specs are similar to the HP-2116B, but the price of the basic $8 \mathrm{~K}$ unit is 14,000; with a $32 \mathrm{~K}$-word memory. the $2116 C$ is $\$ 24,000$.

\section{HP-2100A}

The more recent HP-2100A computer is priced at $\$ 3,750$ without memory modules. The basic cost includes operator's panel, extended arithmetic instructions, memory parity check without interrupt, power-fail interrupt with auto restart, memory protect. and 14 input/output locations. $A$ KK memory module is 83,$500 ; 8 \mathrm{~K}$ is 87,000 $16 \mathrm{~K}$ is $\$ 21,000$. An input/output extender (\$3,500) provides power supplies and prewired slots for 31 additional $1 / 0$ channels. The HP-2100A has a folded planar core memory, 16-bit words, and a cycle time of 980 nsec. Multiply time is 10.7 microsec.

\section{General Automation, Inc.}

Automation Products Div.

706 West Katella

Orange, Calif. 92667

\section{GA $18 / 30$}

The Model GA $18 / 30$ is software-compatible with IBM's 1130 and 1800, hence the designation $18 / 30$. The system has a 16-bit word length, single- and double-precision arithmetic hardware multiply-divide plus parity and storage protection bits. The processor has a 960-nsec memory with the basic $4 \mathrm{~K}$ expandable to 32K and a 16-word 35-nsec scratch pad. There are six classes of instructions with over 400 modifications. Add time (single prectsion) is 2.4 microsec, multiply time is 12.0 microsec, and data channel transfers, 1.2 microsec. Maximum word transfer rate is $960 \mathrm{kHz}$. Software is program-compatible with the two IBM machines and includes FORTRAN, assemblers, and real-time executives. Price of the basic system was about $\$ 18,000$; the cost was $\$ 19,500$ with ASR-33. The unit takes $19 \times 15 \% \times 221 / 4$ in. of rack space and weighs 85 to $105 \mathrm{lb}$, depending on options.

\section{Minuteman D17B}

For Minuteman D17B computer purchasing information write: Defense Supply Agency, Reutilization Office, Headquarters, Cameron Station, Alexandria, Va. 22314. Refer to: DSAH-LSR.

For information covering a D17B technical data package write: North American Rockwell Corp., Autonetics Division, 3770 Miraloma, Anaheim, Calif 92803.

6. Several Minuteman computer owners are listed below.

Beaver College, Psychology, Glenside, Pa. (Dr. B. Maumer)

Bowling Green State University. Psychology, Bowling Green, Ohio (Dr. R. Tweney)

University of Colorado, Psychology. Boulder, Colo. (Director CLIPR)

Louidana State University, Neurology. New Orlenns, La. (Dx. Lee Happel)

Medical Univertity of South Carolina. Neurosurgery, Charleston, S.C. (Chairman)

M.I.T. Educational Research Center. Cambridge, Mans. (Director)

Princeton Univerdity, Psycholosy. Princeton, N.J.
Florida State University, Center for Computer Assisted Instruction. Tallahassee, Fla. (Dr. Paul Merrill)

University of Virginia, Psychology, Charlottesville, Va.

For information on the D17B Users' Group, write to Charles E. Beck, Systems Lab of Electrical Engineering, Tulane University, New Orleans, La. 70118.

7. INTERACT Users (Lehigh Valley Electronics)

J. R. Millenson, Institute of Experimental Psychology, University of $\mathrm{Ox}$ ford, Oxford, England (uses ACT)

H. Coppock, Psychology, University of Wisconain-Patkside, Kenosha, Wis.

H. Keith Rodewald, Psycholozy, Central Michiran University, Mt. Pleasant. Mich.

Harlyn Hamm, Psychology, Northern Michigan University, Marquette, Mich.

Harold Strub, University of Winnipeg. Winnipes, Man., Canada

\section{SCAT System Users (Grason-Stadler)}

J. Gilbert, Psychology. Florida State University, Tallahassee, Fla.

A. Amsel, Psychology, University of Texas, Austin, Tex.

R. Benton, University of Texas Medical School, R.E.A.C.T. Galveston, Tex.

J. Davenport, University of Wisconsin, Regional Primate Research Center, Madison, Wis.

J. L. Slanger, Rudolph Magnus Institute, University of Utrecht, Utrecht, The Netherlands

R. Monty, Aberdeen Proving Grounds, Human Research Center, Aberdeen, Md.

B. Weiss, Radiation Biology and Biophysics, University of Rochester. School of Medicine, Rochester, N.Y. (Used SCAT software and hardware with his own PDP-12)

\section{DEC Users Group}

Mrs. Angela Cossette, Executive Director, pigital Equipment Computer Users Society, Maynard, Mass. 01754

(DECUS Program Libraxy information at same address.)

\section{NOVA and SUPERNOVA Users Group}

Robert C. Baskin, Executive Secretary, Users' Group, Data General Corp. Southboro, Mass. 01772

For Protram Abstracts: Data General Corp. Program Library, Southboro. Mass, 01772

\section{VARIAN Users Group}

Executive Secretary, Users' Group, Varian Date Machines, 2722 Michelson Dr., Irvine, Calif. 92664

\section{Hewlett-Packard User (Information)}

\footnotetext{
John J. Post, Mazeting Support, Hewlett-Packard, Medical Electronics Div. 175 Wymm st. Waltham, Mass. 02154
} 